\title{
Piezo-Sensitive Fabrics from Carbon Black Containing Conductive Cellulose Fibres for Flexible Pressure Sensors
}

\author{
Julia Ullrich ${ }^{1}$, Martin Eisenreich ${ }^{1}$, Yvonne Zimmermann ${ }^{1}$, Dominik Mayer ${ }^{2}$, Nina Koehne ${ }^{2}$, \\ Jacqueline F. Tschannett ${ }^{3,+}$, Amalid Mahmud-Ali ${ }^{3,+}$ and Thomas Bechtold ${ }^{3, *}+$ (D) \\ 1 Textilforschungsinstitut Thüringen-Vogtland e.V., Zeulenrodaer Straße 42, D-07973 Greiz, Germany; \\ j.ullrich@titv-greiz.de (J.U.); m.eisenreich@titv-greiz.de (M.E.); y.zimmermann@titv-greiz.de (Y.Z.) \\ 2 Kelheim Fibres GmbH, Regensburger Straße 109, D-93309 Kelheim, Germany; \\ Dominik.Mayer@kelheim-fibres.com (D.M.); Nina.Koehne@kelheim-fibres.com (N.K.) \\ 3 Research Institute of Textile Chemistry and Textile Physics, Leopold-Franzens-University of Innsbruck, \\ Hoechsterstraße 73, A-6850 Dornbirn, Austria; Jacqueline.Tschannett@uibk.ac.at (J.F.T.); \\ Amalid.Mahmud-Ali@uibk.ac.at (A.M.-A.) \\ * Correspondence: thomas.bechtold@uibk.ac.at; Tel.: +43-(0)-5572-28533 \\ + Research Institute of Textile Chemistry and Textile Physics: Member of EPNOE-European Polysaccharide \\ Network of Excellence, www.epnoe.eu.
}

Received: 18 October 2020; Accepted: 13 November 2020; Published: 16 November 2020

\begin{abstract}
The design of flexible sensors which can be incorporated in textile structures is of decisive importance for the future development of wearables. In addition to their technical functionality, the materials chosen to construct the sensor should be nontoxic, affordable, and compatible with future recycling. Conductive fibres were produced by incorporation of carbon black into regenerated cellulose fibres. By incorporation of $23 \mathrm{wt} . \%$ and $27 \mathrm{wt} . \%$ carbon black, the surface resistance of the fibres reduced from $1.3 \times 10^{10} \Omega \cdot \mathrm{cm}$ for standard viscose fibres to $2.7 \times 10^{3}$ and $475 \Omega \cdot \mathrm{cm}$, respectively. Fibre tenacity reduced to $30-50 \%$ of a standard viscose; however, it was sufficient to allow processing of the material in standard textile operations. A fibre blend of the conductive viscose fibres with polyester fibres was used to produce a needle-punched nonwoven material with piezo-electric properties, which was used as a pressure sensor in the very low pressure range of 400-1000 Pa. The durability of the sensor was demonstrated in repetitive load/relaxation cycles. As a regenerated cellulose fibre, the carbon-black-incorporated cellulose fibre is compatible with standard textile processing operations and, thus, will be of high interest as a functional element in future wearables.
\end{abstract}

Keywords: conductive fibres; cellulose fibres; pressure sensor; smart textiles; viscose fibres; carbon black

\section{Introduction}

The Scientific and Technology Options Assessment Panel of the European Parliament (STOA) identified wearables as one of the 10 technologies which will change our lives with very promising market prospects for wearables, forecasted to increase to USD 150 billion by 2026 [1]. The introduction of sensors and electronic devices into textile products allows integration of additional functionalities and opens access to the market of intelligent products for new applications [2].

The integration of electrical devices into textiles requires development of flexible conductive structures and the availability of sensor systems to translate external physical stimuli into electrical signals $[3,4]$. The intended application of a product determines selection of a certain sensor principle; 
thus, dependent on the technical requirements, a wide number of different sensor concepts have been developed for a given physical parameter [5].

A number of principles have been reported in the literature for measurement of pressure, i.e., force per area, e.g., via measurement of electrical capacity [6], resistivity [7,8], or optical effects [9]. Changes in inductance and the corresponding resonant frequency of circuits were also proposed as a principle to operate a pressure sensor [10].

The combination of conductive films and deformable insulating layers permits construction of capacitors with pressure-sensitive capacity [11-13]. Similarly, two conductive lines, woven into a fabric or wrapped in ply structure and separated by an elastic material, have been proposed as thread-like capacitive pressure sensors [14-16].

In another approach, the piezo-resistive properties of compressible structures were used to build flexible textile-based pressure sensors $[17,18]$. Space-resolved pressure-sensitive layers have been assembled via a combination of piezo-resistive nonwoven material and conductive elements with the aim to develop pressure sensors in shoes [19]. Other approaches integrated elastic piezo-sensitive layers in sensor pads [20], shoes [21], seats [22,23], sensor mats [24], and carpets [25-27].

In many cases, the sensor element in such devices is built from a compressible conductive material which then changes its electrical resistance upon compression through external forces [28]. The conductive structure is often a web fabric containing conductive fibres [29]. Furthermore, carbon-nanotube-coated three-dimensional (3D) spacer textiles or conductive silicones have been proposed as pressure-sensitive flexible structures [30-32].

Higher electrical conductivity is required for the electrical connections between sensor and data processor. Thus, metal-based coatings of threads, braided wires, and wrapped yarns with the use of thin metal films are used [3]. These lines should exhibit low electrical resistance; thus, contribution of the electrical connection to the total resistance of a device remains in the dimension of a few ohms.

Different types of conductive fibre-based structures can be applied to build a pressure-sensitive structure, e.g., use of conductive polymers [33], fibre coatings with carbon-based layers [34], or integration of conductive material into fibres to obtain intrinsically conductive fibres. Moreover, formation of carbon foam through carbonisation of melamine foam has been reported as a route to prepare flexible conductive structures [35].

Conductive cellulose fibres can be obtained using a number of techniques, e.g., electroless deposition of metal layers on the fibre surface or incorporation of a conductive material, e.g., graphite, carbon black (CB), or carbon nanotubes, into the fibre matrix during fibre production [36,37]. In the viscose process, cellulose at first is steeped in concentrated $\mathrm{NaOH}$ solution. The formed alkali cellulose is then reacted with carbon disulphide to form the alkali-soluble cellulose xanthogenate. The aqueous alkaline solution of the cellulose xanthogenate is then spun into a coagulation bath containing a mixture of $\mathrm{Na}_{2} \mathrm{SO}_{4}$ and $\mathrm{H}_{2} \mathrm{SO}_{4}$. In the acidic coagulation bath, at first, coagulation of the xanthogenate occurs, then hydrolysis of the xanthogenate into cellulose and carbon disulphide takes place. The chemical inertness of $\mathrm{CB}$ makes this material favourable for incorporation during the viscose fibre formation, as the rather harsh chemical conditions applied during the viscose fibre process cause surface corrosion of metal particles such as $\mathrm{Ag}$ and $\mathrm{Cu}$.

In addition to chemical inertness during the process of viscose fibre formation, the conductive additives must not disturb the process of fibre spinning through agglomeration and formation of larger particle structures, which then clog the bores of the spinneret [37].

$\mathrm{CB}$ is technically used as a pigment for printing and paint formulation. This nontoxic material is available in bulk amounts and at low costs. Thus, research on the incorporation of CB in viscose fibres for production of conductive cellulose is of high interest to elaborate the fundamentals of a scalable and commercially viable technical process. In this study, the formation of conductive viscose fibres through incorporation of $\mathrm{CB}$ was studied as a function of added CB. The fibres were characterised by scanning electron microscopy, conductivity measurement, and determination of fibre strength. The conductive 
viscose fibres were processed into fibre webs to obtain plane piezo-sensitive layers, which were characterised in static and cyclic load experiments for their functionality as pressure sensors.

\section{Experimental}

\subsection{Preparation and Characterisation of Conductive Viscose Fibres}

As a first step, an aqueous dispersion of $20 \mathrm{wt} \%$ carbon black (CB, low structure, regular colour furnace (RCG), average particle size 27 nm; Printex 300, Orion Engineered Carbons, Luxemburg) was prepared with use of an anionic surfactant as dispersant (sodium lignosulphonate). The dispersion was then added to the standard spinning dope (10 wt.\% cellulose) to obtain spinning dopes with 3.2, 10, and $30 \mathrm{wt} . \%$ CB. Laboratory spinning devices and a pilot-scale spinning unit (both Kelheim Fibres, Kelheim, Germany) were used for viscose fibre production. The viscose dope was filtered and spun to viscose fibres with fineness of 1.7 or 3.3 dtex.

The actual content of $\mathrm{CB}$ in the viscose fibres was determined by photometry (double-beam spectrophotometer, Perkin Elmer Lambda 25, Rodgau, Germany).

Laser scanning microscopy of CB-incorporated viscose fibres was undertaken with a laser scanning 3D microscope (VK-X100 series LSM 3D Profile Measurement, KEYENCE, Tokyo, Japan).

Scanning electron microscope photos (SEM) of the fibres were taken with use of a DSM 940A electron microscope (Zeiss, Oberkochen, Germany).

Fibre tenacity and elongation to break were measured using a single-fibre tensile strength tester on the basis of DIN EN ISO 5079 (Fafegraph HR in combination with Vibromat ME, Textechno, Mönchengladbach, Germany). The fineness of the fibres was determined using the vibrational method on the basis of DIN EN ISO 1973 (Vibromat ME, Textechno, Mönchengladbach, Germany).

To characterise fibres in an oriented arrangement, so-called rotor rings were prepared. A mass of $10 \mathrm{~g}$ fibres was processed into a parallelised fibre band (Device built by ITV-Denkendorf, Denkendorf, Germany). The surface resistance along the fibre band was measured with a multimeter (Figure S1, Supplementary Materials; Fluke 1587, Glottertal, Germany). To determine the volume resistivity, the fibre rotor ring was packed between two copper plates with $1 \mathrm{~cm}$ distance, and the electrical resistance was measured. The fibre conductivity was calculated as the reciprocal value of the measured electrical resistance.

Additionally, the specific surface resistance and the volume resistance of rotor rings were measured using a ring electrode according to DIN EN 1149-1:2006-09. The measurements were undertaken at three different climate conditions $\left(20^{\circ} \mathrm{C}, 65 \%\right.$ relative humidity $(\mathrm{RH}), 23^{\circ} \mathrm{C}, 50 \% \mathrm{RH}$, and $\left.23{ }^{\circ} \mathrm{C}, 40 \% \mathrm{RH}\right)$. The samples were conditioned in the respective climate for $24 \mathrm{~h}$ before measurement. Rotor rings were cut into pieces of $20 \mathrm{~mm}$ length, and a mass of $5 \mathrm{~g}$ was placed in the ring electrode. A ring electrode with $50.4 \mathrm{~mm}$ diameter and a mass of $460 \mathrm{~g}$ was used to compress the fibres (Textilelektrode TE 50, H.-P. Fischer Elektronik GmbH\&Co, Industrie und Labortechnik KG, Mittenwalde, Germany). The surface and volume resistances were determined with a tera-ohm meter according to DIN EN 1149 (Figure S2, Supplementary Materials; Milli-Tera-Ohmmeter Milli-TO 3, H.-P. Fischer Elektronik $\mathrm{GmbH \& Co}$, Industrie und Labortechnik KG).

Fibre samples were processed into yarn using a lab spinning unit (Kelheim fibres, Germany). The determination of the yarn resistance for a length of $10 \mathrm{~cm}$ was performed using a textile stripe electrode and a tera-ohm meter (Figure S3, Supplementary Materials; Textilstreifenelektrode TSE 1, H.-P. Fischer Elektronik GmbH\&Co, Industrie und Labortechnik KG). Readings were taken after $60 \mathrm{~s}$ of equilibration. Results are given as the mean value of five repetitions.

Nonwoven fabrics (mass per area $250 \mathrm{~g} / \mathrm{m}^{2}$ ) were prepared through needle punching to obtain a piezo-resistive structure. 


\subsection{Preparation and Characterisation of Piezo-Resistive Nonwovens}

A nonwoven material made from 100\% viscose fibres (No. 7, $3.3 \mathrm{dtex}, 40 \mathrm{~mm}, 23 \mathrm{wt} . \% \mathrm{CB}$ ) was used to study the piezo-electric behaviour of the material. The plane samples then were placed between two conductive metal foils. The sandwich was placed on a balance, and compression of the web was achieved by stepwise increase of the weight placed on top of the assembly (area $56.8 \mathrm{~cm}^{2}$ ). A photograph of the set-up is given in Figure S4 (Supplementary Materials). The resistance between the top foil and the bottom foil was measured by means of a laboratory multimeter. Three repetitive cycles of a stepwise increase in pressure, followed by stepwise relaxation of pressure, were performed to analyse the recovery after compression. Results are given as the mean value and standard deviation of three independent experiments.

In a next approach, the conductive viscose fibres were blended with synthetic fibres to improve elastic recovery of the nonwoven fabrics. Two different types of nonwoven fabric were prepared with use of a 3.3 dtex viscose fibre (No. 8, 27 wt. $\%$ CB content):

Material A contained $50 \mathrm{wt} . \%$ CB-incorporated viscose (3.3 dtex, fibre length $40 \mathrm{~mm}$ ) and $50 \mathrm{wt} . \%$ polyester fibre (3.3 dtex, fibre length $60 \mathrm{~mm}$ ).

Material B contained $65 \mathrm{wt} . \%$ CB-incorporated viscose (3.3 dtex, fibre length $40 \mathrm{~mm}$ ), $30 \mathrm{wt} . \%$ polyester fibre ( $3.3 \mathrm{dtex}$, fibre length $60 \mathrm{~mm}$ ), and $5 \mathrm{wt} . \%$ polyester bi-component fibre (2.2 dtex, fibre length $51 \mathrm{~mm}$ ).

For the repetitive load/relaxation cycles, a modified tensile testing unit was used (Zwick Roell Z010). A sandwich structure $(100 \mathrm{~mm} \times 100 \mathrm{~mm})$ of two copper plates with a conductive fibre web as the middle structure was mounted in the testing device (Figure S5, Supplementary Materials). A series of $50 \mathrm{load} /$ relaxation cycles was performed, and the change in conductivity as a function of applied pressure was recorded. The cycling was performed within pressure limits of $500 \mathrm{~Pa}\left(5 \mathrm{~N} / 100 \mathrm{~cm}^{2}\right)$ and $2300 \mathrm{~Pa}\left(230 \mathrm{~N} / 100 \mathrm{~cm}^{2}\right)$.

\section{Results and Discussion}

\subsection{Fibre Characterisation}

The $\mathrm{CB}$ was added to the spinning dope in the form of a CB dispersion, which was stabilised by addition of an anionic or nonionic dispersant. The concentration of the conductive material and the state of dispersion of the $\mathrm{CB}$ in the fibre determined the final $\mathrm{CB}$ content in the fibre and the measured electrical conductivity. The percolation threshold, as well as the fibre conductivity, depended on the amount of conductive additive, the particle size, and distribution in the fibre. Through dispersion with a high shear rate and addition of a dispersing agent, the particle size of the dispersion could be kept below $10 \mu \mathrm{m}$, which is a prerequisite to avoid blocking of the spinneret. Immediately before fibre spinning, any larger aggregates of $\mathrm{CB}$ were removed by filtration. At the stage of fibre regeneration, weakly bound $\mathrm{CB}$ was washed out into the coagulation bath. Thus, the analytically determined amount of $\mathrm{CB}$ incorporated in the fibres was lower than the theoretical amount of $\mathrm{CB}$ calculated from the addition of $C B$ to the spin dope.

The conductivity of the fibres increased with increasing content of $\mathrm{CB}$; however, as a result of the presence of dispersed $\mathrm{CB}$, a reduction in mechanical properties of the fibres was observed in parallel. The increase in fibre conductivity and the decrease in tenacity and elongation with increasing content of CB are shown in Table 1. A substantial reduction in tenacity was observed at a CB content above $10 \mathrm{wt} . \%$. The threshold for an increase in conductivity was reached at $15 \mathrm{wt} . \%$ CB incorporation, which indicates the lower limit for percolation of the $\mathrm{CB}$ particles inside the fibre structure (Figure 1). 
Table 1. Mechanical and electrical properties of viscose fibres as a function of carbon black (CB) content added to the spin dope (fibre length 40 mm).

\begin{tabular}{|c|c|c|c|c|c|c|c|c|}
\hline \multirow{2}{*}{ No. } & Fibre Fineness & CB Added & CB Incorporated & CB Loss & Tenacity & Elongation & Surface Resistance & Conductivity \\
\hline & dtex & $\%$ & $\%$ & $\%$ & cN/tex & $\%$ & $\Omega \cdot \mathrm{cm}$ & $\mathrm{S} / \mathrm{m}$ \\
\hline 1 & 3.3 & 0 & 0 & 0.00 & 20.5 & 24 & $1.3 \times 10^{10}$ & $7.7 \times 10^{-9}$ \\
\hline 2 & 1.7 & 0 & 0 & 0.00 & 26 & 20 & $1.3 \times 10^{10}$ & $7.7 \times 10^{-9}$ \\
\hline 3 & 1.7 & 3.2 & 3.2 & -0.3 & 21.2 & 24.0 & $1.3 \times 10^{10}$ & $7.7 \times 10^{-9}$ \\
\hline 4 & 1.7 & 10 & 7.3 & 26.9 & 12.7 & 17.4 & $1.3 \times 10^{10}$ & $7.7 \times 10^{-9}$ \\
\hline 5 & 3.3 & 20 & 16.4 & 18.0 & 7.9 & 15.6 & $1.1 \times 10^{9}$ & $9.4 \times 10^{-8}$ \\
\hline 6 & 3.3 & 25 & 19.8 & 20.6 & 7.1 & 14.5 & $11.4 \times 10^{6}$ & $8.8 \times 10^{-6}$ \\
\hline 7 & 3.3 & 30 & 23.1 & 23.2 & 6.9 & 15.2 & $2.7 \times 10^{3}$ & 0.044 \\
\hline 8 & 3.3 & 36.7 & 27.2 & 25.9 & 9.53 & 30.35 & 475 & 0.210 \\
\hline
\end{tabular}




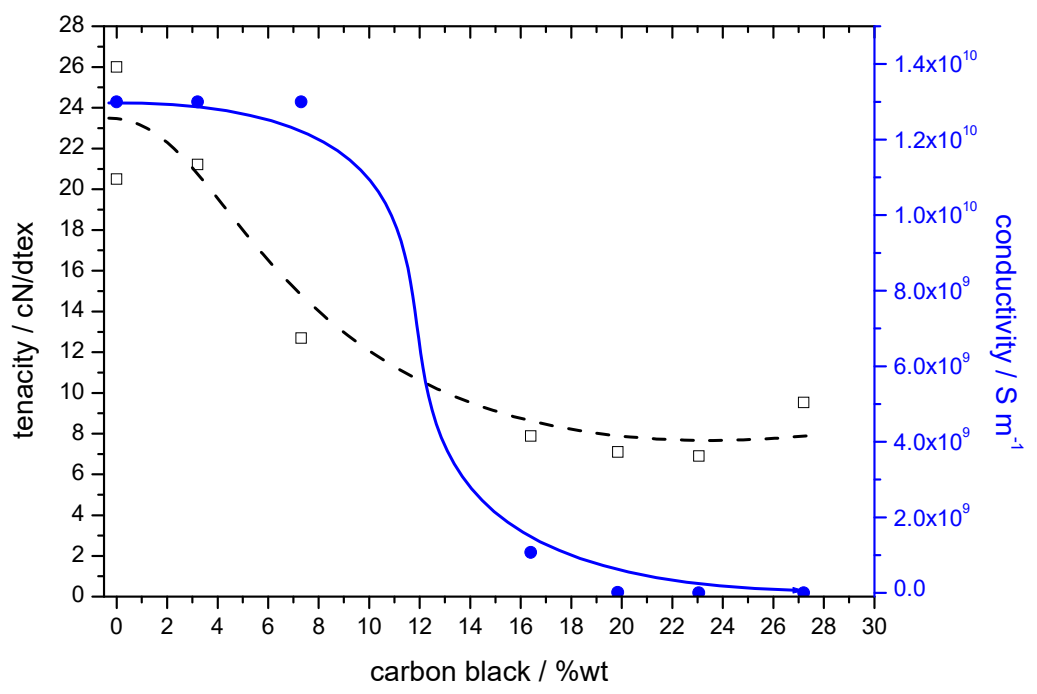

Figure 1. Tenacity and conductivity of viscose fibres as a function of the analytically determined CB content.

Fibres with different content in $\mathrm{CB}$ and a standard viscose fibre without addition of $\mathrm{CB}$ were analysed by laser scanning microscopy. Fibres with $23.1 \mathrm{wt} . \% \mathrm{CB}$ content were then selected for scanning electron microscopy, to visualise the state of dispersion of the $\mathrm{CB}$ in the fibres using a higher resolution. Representative examples are shown in Figures 2 and 3.

When compared to the surface of a standard viscose fibre (Figure 2e) the incorporation of $\mathrm{CB}$ led to an increasingly rougher surface (Figure 2a-d). In particular, at high concentration of $\mathrm{CB}$ (Figures $2 \mathrm{~d}$ and $3 \mathrm{a}$ ), the presence of $\mathrm{CB}$ particles could be observed in the photomicrographs. Bigger agglomerates also led to the appearance of bulges at the fibre surface. In viscose fibre spinning, the cellulose fibre was regenerated from a diluted alkaline solution, which contained approximately $10 \mathrm{wt}$.\% cellulose. During fibre regeneration, solid cellulose forms and a substantial shrinkage in cellulose structure occurred. As an estimate, the area of the cross-section was reduced to $10-15 \%$ of the initially extruded viscose solution, and the diameter was reduced to one-third. The dimensions of the $\mathrm{CB}$ agglomerates in the dope remained constant; thus, visible bulges began to appear at the fibre surface at higher $\mathrm{CB}$ content and larger agglomerates appeared at the fibre surface (Figure 2d,e). The diameter of these agglomerates was still substantially smaller than the diameter of the regenerated fibre, as larger agglomerates were already filtered off before the spinning dope passed the spinneret. The presence of a few larger agglomerates of CB can also be observed in the SEM photomicrographs taken with fibres containing 27.2 wt.\% CB. Most of the CB, however, was present inside the fibre in highly dispersed form, which was the condition to achieve percolation and electrical conductivity.

The increase in conductivity with $\mathrm{CB}$ content and the moisture dependence of the volume resistivity were also studied in measurements of the volume resistance at rotor rings (Figure 4). Volume resistance measured with the rotor rings was used to characterise the conductivity of the fibres as bulk material with fibres packed in low oriented state. Measurements at different relative humidity demonstrated the influence of the ambient conditions on the electrical resistivity. Fibres with low conductivity exhibited a substantial reduction in resistance with increasing relative humidity, while fibres with $23.1 \mathrm{wt} . \% \mathrm{CB}$ exhibited an increase in resistance at $65 \% \mathrm{RH}$.

The electrical resistance of yarn samples was measured to characterise the conductive behaviour of the fibres in a longitudinally oriented arrangement. The lower amount of conductive material in the cross-section of a yarn and the longer distance between the contact points led to high electrical resistance compared to the tests with rotor rings. Again, the resistance of the samples was reduced with increasing relative humidity due to the contribution of absorbed water to the overall conductivity (Figure 5). 


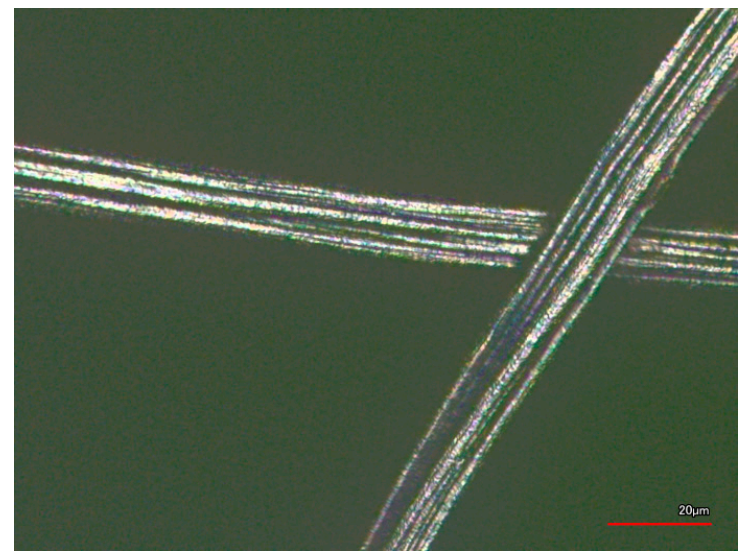

(a)

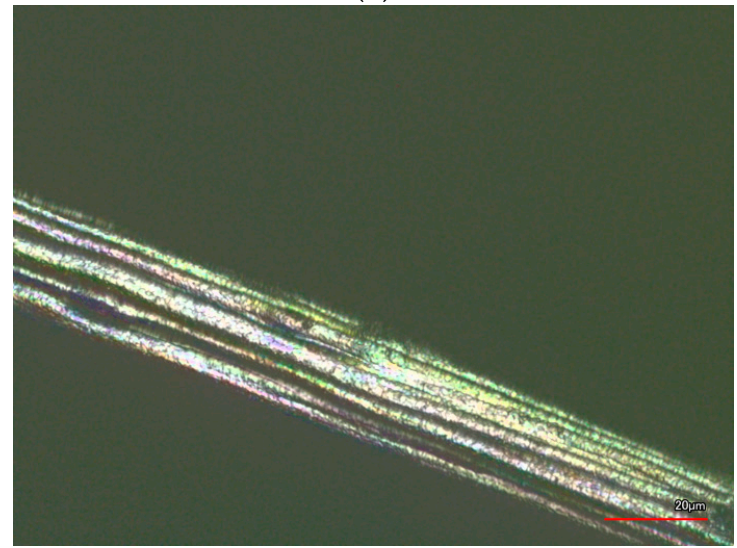

(c)

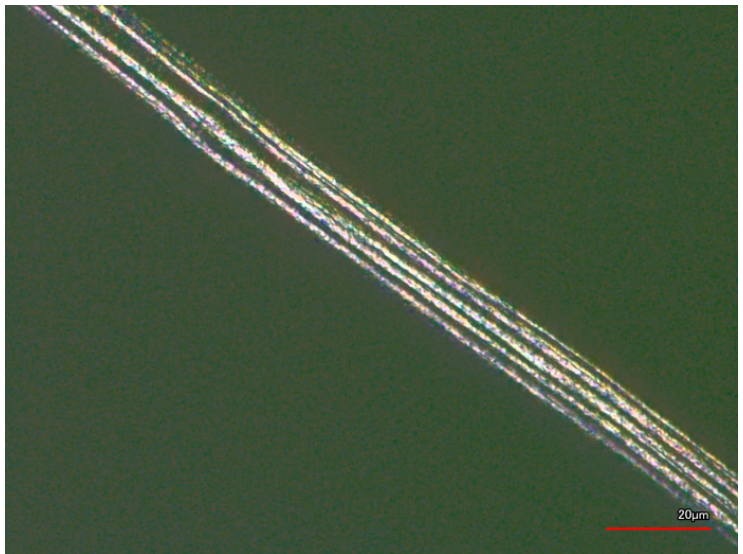

(b)

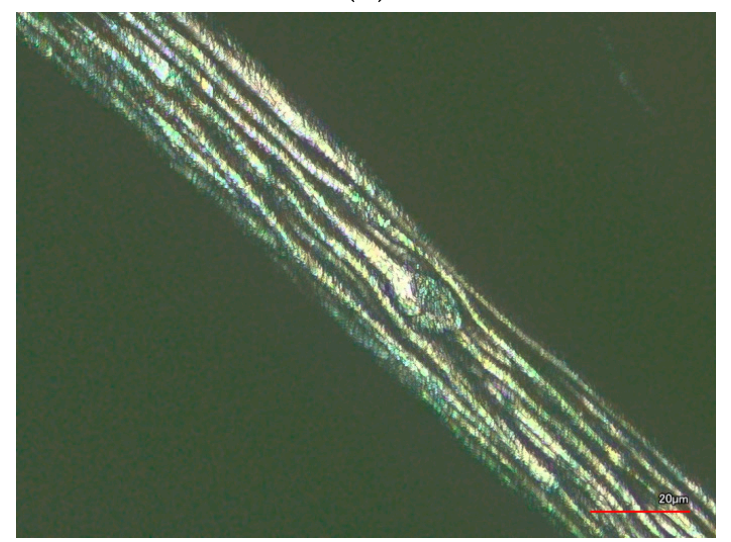

(d)

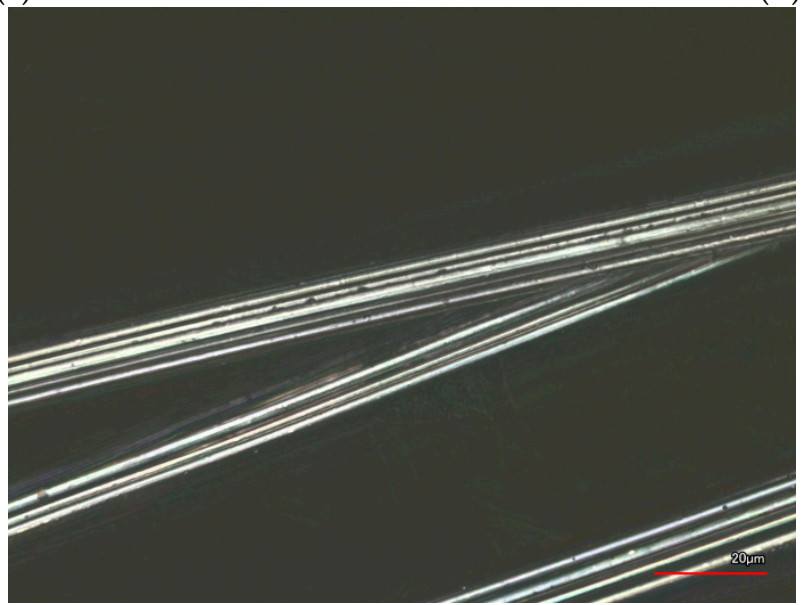

(e)

Figure 2. Laser scanning microscopy of $\mathrm{CB}$ incorporated viscose fibres: (a) sample (4) 1.7 dtex, 7.3 wt.\% CB; (b) sample (5) 1.7 dtex, 16.4 wt.\% CB; (c) sample (7) 3.3 dtex, 23.1 wt.\% CB; (d) sample (8) 3.3 dtex, 27.2 wt.\% CB; (e) standard viscose fibres 1.3 dtex.

All samples exhibited a distinct change in electrical conductivity with a change in relative humidity. The absorption of water into the cellulose structure and on the fibre surface created two effects:

- Water adsorbed in the cellulose structure and on the fibre surface contributed to the overall conductivity; thus, a reduction in resistivity was observed. The contribution to the conductivity was, however, low; thus, this effect was observed only in fibre assemblies which exhibited a relatively low conductivity. Thus, in the case of fibres assemblies with a volume resistance on the magnitude of gigaohms, the uptake of moisture contributed to the relatively low conductivity. 
- The adsorption of water molecules also led to changes in fibre dimensions and to the formation of molecular layers of water on the fibre surface. These effects could lead to a reduction in conductivity, which was observed only in the case of fibre assemblies with volume conductivity in the dimension of several kiloohms. Here, the uptake of moisture reduced the level of percolation, e.g., through hygral fibre expansion, thus leading to a reduction in conductivity with increasing moisture content (Figure 5).

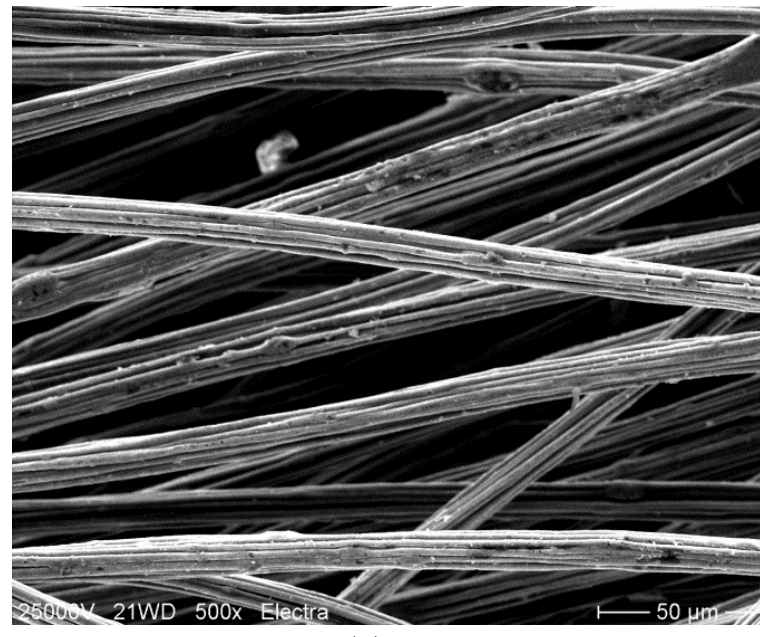

(a)

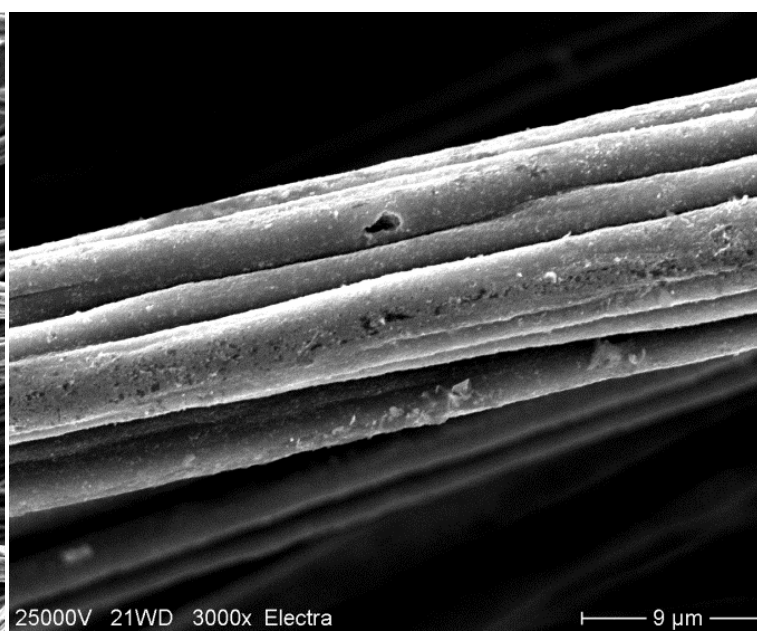

(b)

Figure 3. Scanning electron microscopy of CB-incorporated viscose fibres (8) (3.3 dtex, $27.2 \mathrm{wt}$. \% CB); (a) magnification $500 \times$, (b) magnification $3000 \times$.

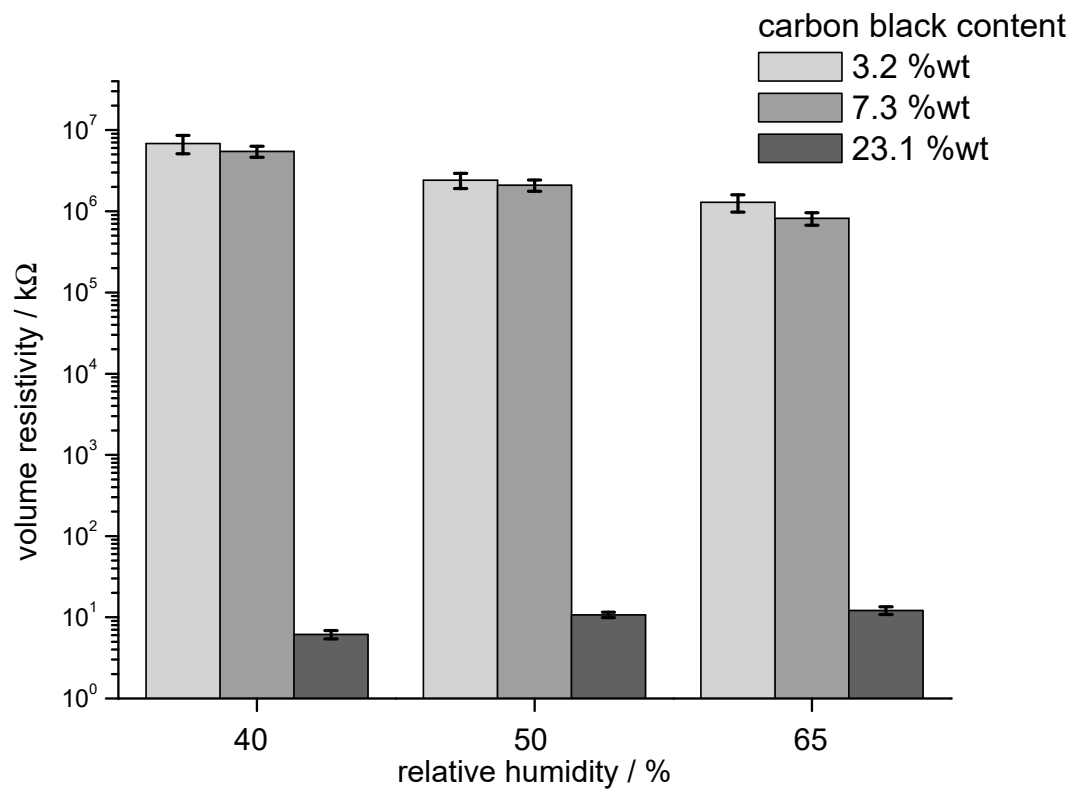

Figure 4. Volume resistivity of rotor rings measured at $40 \% \mathrm{RH}, 50 \% \mathrm{RH}$, and $65 \% \mathrm{RH}$ as a function of incorporated CB: sample (3) 3.2 wt.\% CB, sample (4) 7.3 wt.\% CB, and sample (7) 23.1 wt.\% CB. 


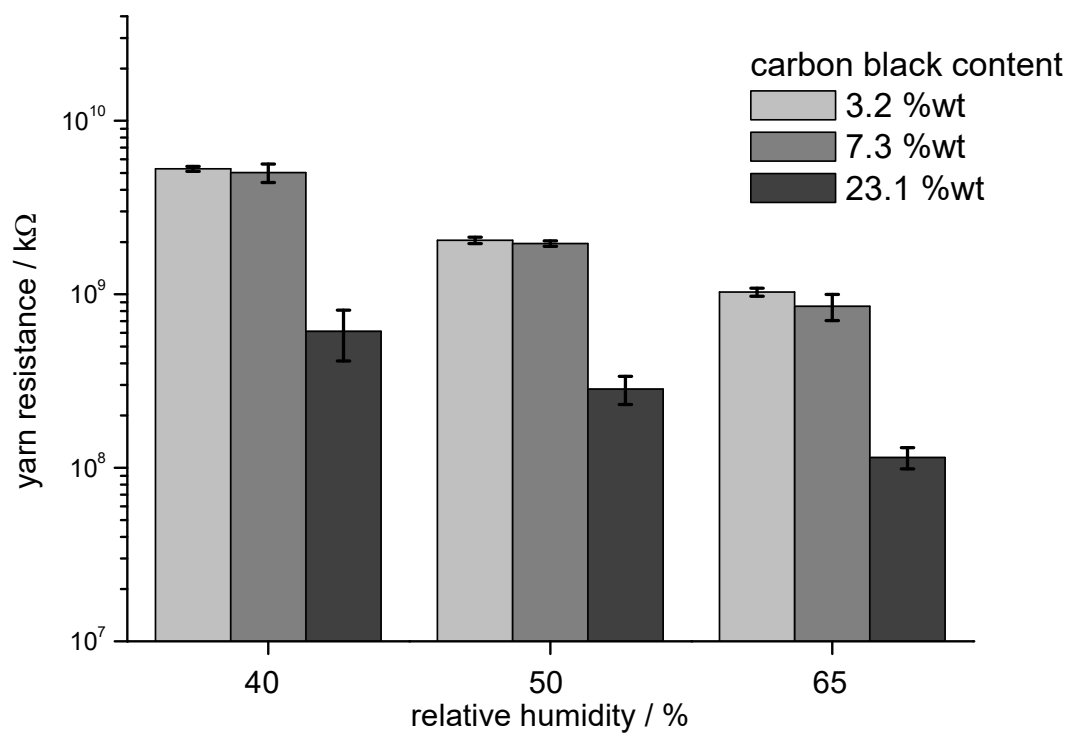

Figure 5. Yarn resistance (measured over a length of $10 \mathrm{~cm}$ ) measured at $40 \% \mathrm{RH}, 50 \% \mathrm{RH}$, and $65 \% \mathrm{RH}$ as a function of incorporated CB: sample (3) $3.2 \mathrm{wt} . \% \mathrm{CB}$, sample (4) $7.3 \mathrm{wt} \% \mathrm{CB}$, and sample (7) 23.1 wt. $\%$ CB.

\subsection{Needle-Punched Nonwoven Material as a Pressure Sensor}

A needle-punched nonwoven material consisting of $100 \%$ conductive viscose fibre (sample (7), 3.3 dtex, fibre length $40 \mathrm{~mm}, 23.1 \mathrm{wt} . \% \mathrm{CB}$ ) was used as a piezo-sensitive layer. A representative example for the compression/relaxation behaviour during three repetitive load/relaxation cycles is given in Figure 6.

The results in Figure 6 demonstrate the pressure sensitivity of the electrical resistance of a needle-punched fibre nonwoven material in the low-pressure region between 200 and $1000 \mathrm{~Pa}$. At a load below $400 \mathrm{~Pa}$, hysteresis between pressure increase and relaxation appeared. During the expansion of the nonwoven material, a higher number of contact points in the nonwoven region and a higher resistance were observed during the phase of relaxation. During the first cycle, fibres in the nonwoven realigned into a more stable structure; thus, the resistance measured during the following load/relaxation cycles stabilised. In the pressure range between 400 and $1000 \mathrm{~Pa}$, a stable relationship and minimal hysteresis between applied pressure and electrical resistance of the nonwoven material were observed.

To improve the load/relaxation behaviour of the nonwoven material, the conductive viscose fibres were blended with more elastic polyester fibres and polyester bicomponent fibres. These fibres contributed to the recovery of the compressed fibre nonwoven material during the relaxation. Two types of samples were studied:

- Material A (50 wt.\% CB-incorporated viscose, $3.3 \mathrm{dtex}$, fibre length $40 \mathrm{~mm}$ and $50 \mathrm{wt} . \%$ polyester fibre, 3.3 dtex, fibre length $60 \mathrm{~mm}$ )

- Material B (65 wt.\% CB-incorporated viscose, $3.3 \mathrm{dtex}$, fibre length $40 \mathrm{~mm}, 30 \mathrm{wt} . \%$ polyester fibre, 3.3 dtex, fibre length $60 \mathrm{~mm}$, and $5 \mathrm{wt} . \%$ polyester bicomponent fibre, $2.2 \mathrm{dtex}$, fibre length $51 \mathrm{~mm}$ ).

The pressure sensitivity of the electrical resistance of the two different nonwoven materials was studied in three repetitive load/relaxation cycles. Results for Material A and Material B are given in Figure 7.

The repeatability and durability of the nonwoven materials under a high number of repetitive load/relaxation cycles were tested using a modified tensile testing unit.

Representative examples for the resistance change during load/relaxation cycles are shown in Figure 8. 


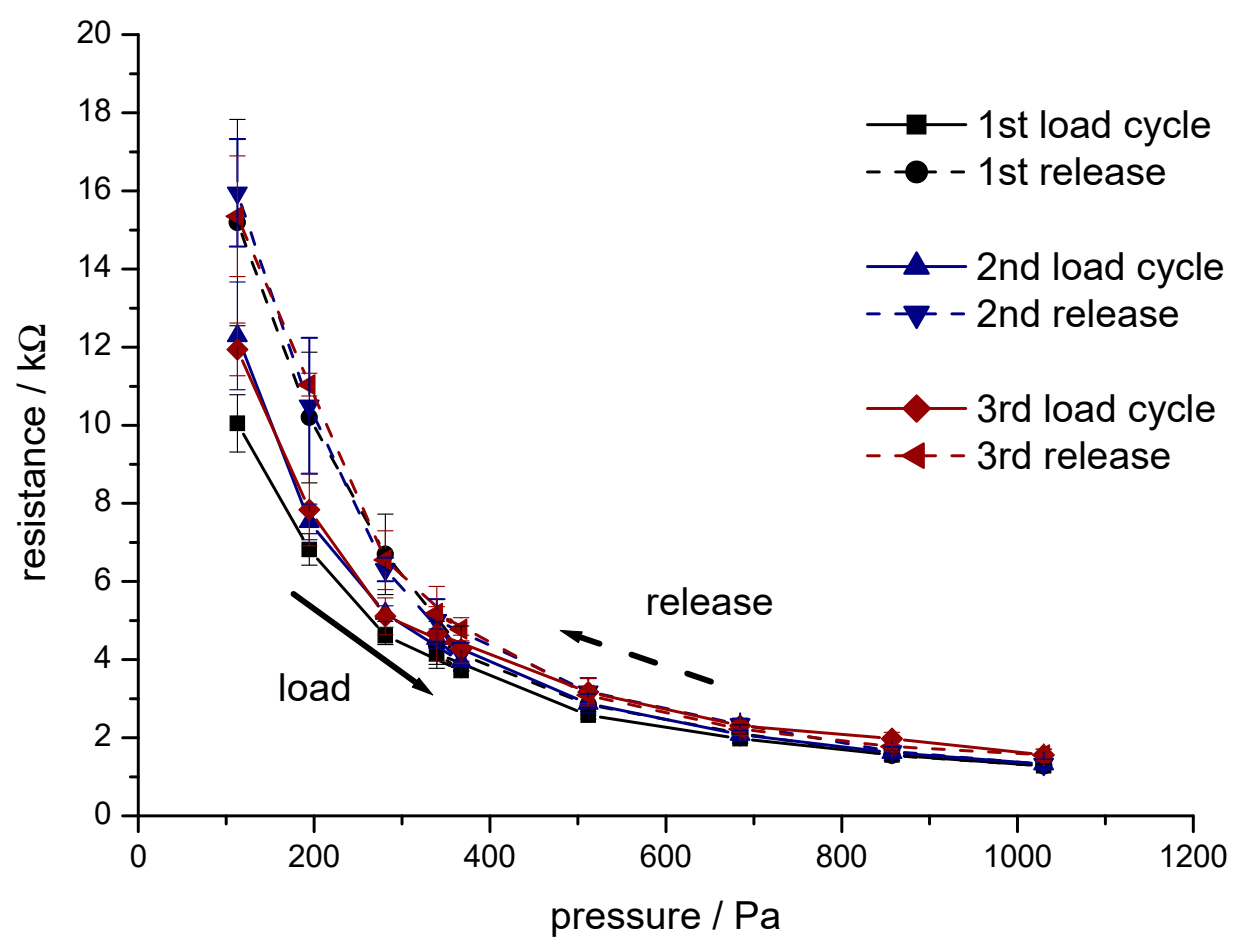

Figure 6. Electrical resistance of a fibre web made of $100 \%$ conductive viscose during three repetitive load relaxation cycles (sample (7), 3.3 dtex, fibre length $40 \mathrm{~mm}, 23.1 \mathrm{wt} . \% \mathrm{CB}$, mass per area $250 \mathrm{~g} / \mathrm{m}^{2}$, test sample area $56.8 \mathrm{~cm}^{2}$ ).

Due to the higher content in conductive fibres, a lower resistance was measured with sample B. The presence of crimped bicomponent fibres in sample B also supported the recovery of the compressed structure and, thus, contributed to a higher signal stability in the cyclic tests.

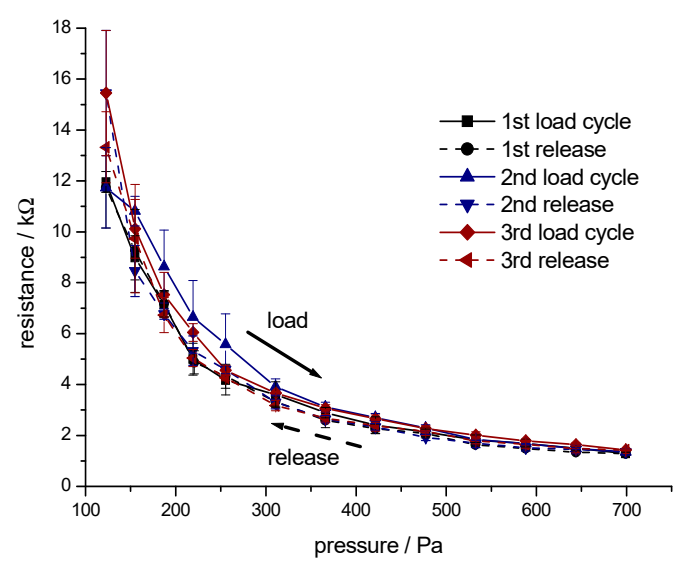

(a)

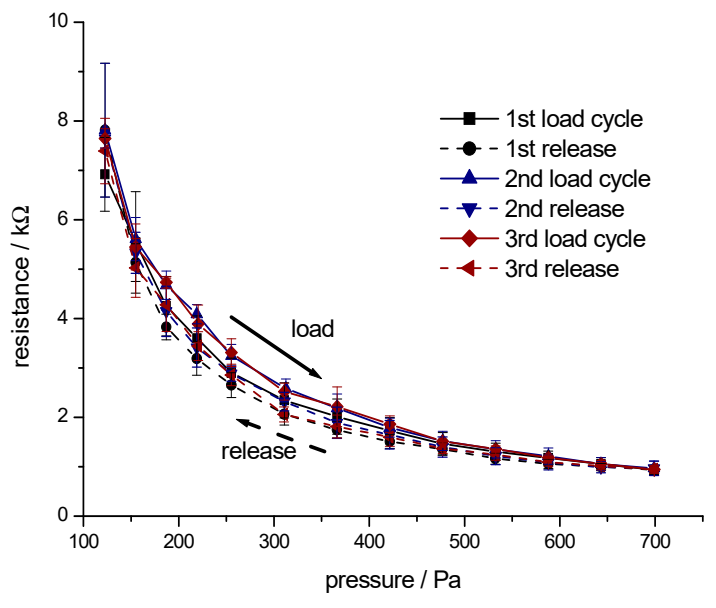

(b)

Figure 7. Electrical resistance of a fibre web made of $100 \%$ conductive viscose during three repetitive load/relaxation cycles: (a) Material A (50 wt.\% CB-incorporated viscose, $3.3 \mathrm{dtex}$, fibre length $40 \mathrm{~mm}$ and $50 \mathrm{wt}$ \% polyester fibre, 3.3 dtex, fibre length $60 \mathrm{~mm}$ ); (b) Material B (65 wt.\% CB-incorporated viscose, 3.3 dtex, fibre length $40 \mathrm{~mm}, 30 \mathrm{wt}$ \% polyester fibre, $3.3 \mathrm{dtex}$, fibre length $60 \mathrm{~mm}$, and $5 \mathrm{wt} \%$ polyester bicomponent fibre, $2.2 \mathrm{dtex}$, fibre length $51 \mathrm{~mm}$ ). 


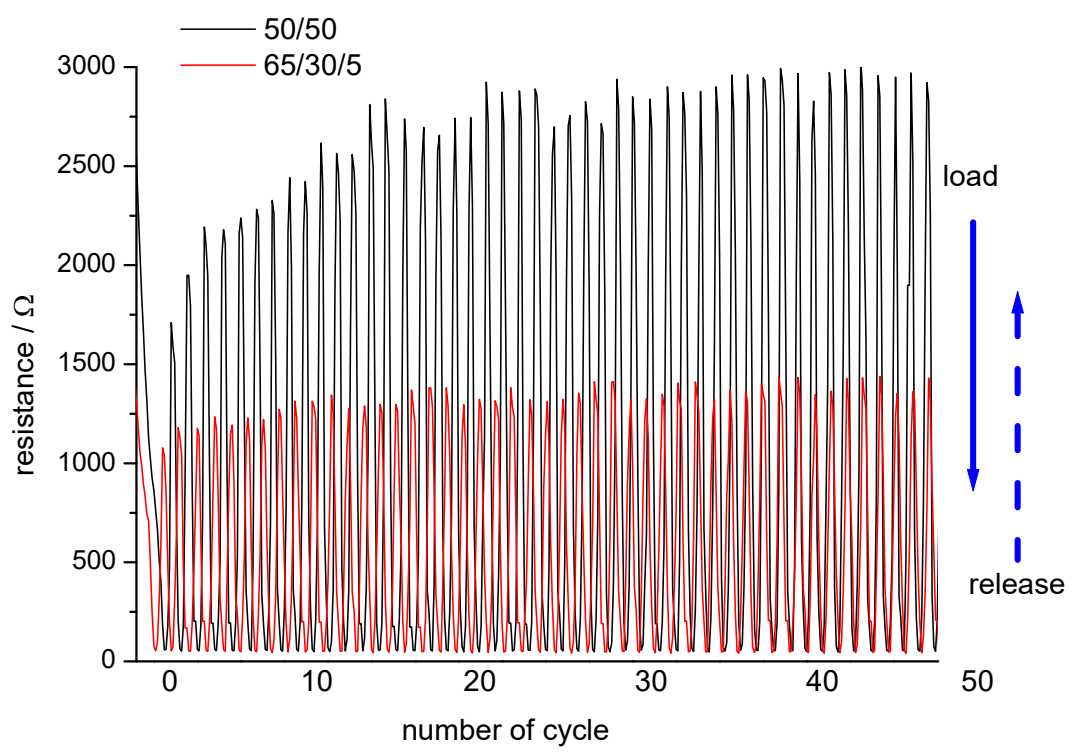

Figure 8. Repeatability and durability of the pressure sensing nonwovens. Resistance change of Material A (50 wt.\% CB-incorporated viscose, $3.3 \mathrm{dtex}$, fibre length $40 \mathrm{~mm}$ and $50 \mathrm{wt} . \%$ polyester fibre, 3.3 dtex, fibre length $60 \mathrm{~mm}$ ) shown in black and Material B (65 wt.\% CB-incorporated viscose, 3.3 dtex, fibre length $40 \mathrm{~mm}, 30 \mathrm{wt}$.\% polyester fibre, $3.3 \mathrm{dtex}$, fibre length $60 \mathrm{~mm}$, and $5 \mathrm{wt} . \%$ polyester bicomponent fibre, $2.2 \mathrm{dtex}$, fibre length $51 \mathrm{~mm}$ ) shown in red during 50 repetitive load/relaxation cycles.

With increasing load, the electrical resistance of samples $A$ and $B$ was reduced to $50 \Omega$ and then increased during the relaxation to the maximum value of $1250 \Omega$ for the Sample B, while, for sample A, higher resistance of 2500-3000 $\Omega$ was observed. The improved mechanical stability of sample B was demonstrated with higher reproducibility of the resistance observed at low pressure. Sample A showed a continuous increase in resistance at low pressure during the first 30 cycles. This was an indication of a prolonged phase of fibre reorganisation in the nonwoven structure in a relaxed state, thus leading to a lower number of contact points available for current transport.

The mechanical stability of Material A and Material B led to a rapid recovery of the electrical resistance when the pressure was reduced to the lower limit (Figure 8). The repeatability and durability of the electrical signal over 50 load/relaxation cycles proved the rapid and reproducible recovery of the conductive structure in unloaded stage. Rupture of brittle fibre segments, breakage of conductive fibres, and loss in the number of electrical contacts in the fibre web would lead to a continuous increase in resistance at low pressure. Both nonwoven materials exhibited very stable signals at the upper pressure limit. A more stable electrical resistance at low pressure was measured with Material B.

The sensor pads exhibited a pressure-sensitive resistance on the magnitude of several kiloohms; thus, measurement of the pressure-dependent signal would be possible with the use of standard electronic devices for data processing. The influence of the electrical resistance of the connections on the signal-evaluating device would then be negligible. A higher sensor resistance, e.g., in the dimension of several megaohms would increase the risk of shunt currents in the electrical connections to the sensor, particularly at high humidity or in a wet state. Piezo-resistive structures with very high resistance would, thus, make the experimental extraction of the pressure dependent signal more difficult.

Changes in relative humidity in the ambient atmosphere would be of substantial influence on the electrical resistance; thus, for practical applications, the nonwoven structure should be covered by either coating or wrapping, to avoid any disturbing influence due to climate-dependent moisture sorption or desorption. 


\section{Conclusions}

Regenerated cellulose fibres can be modified through incorporation of CB to implement electrical conductivity. Addition of $\mathrm{CB}$ into the viscose dope requires formation of stable dispersions and rather high concentrations of $\mathrm{CB}$ to achieve percolation. Through the addition of $20 \mathrm{wt}$ \% CB to the viscose dope, a regenerated cellulose fibre with content of $16.4 \mathrm{wt} \% \mathrm{CB}$ could be obtained. The conductivity of a standard viscose fibre of $7.7 \times 10^{-9}$ increased to $9.4 \times 10^{-8} \mathrm{~S} / \mathrm{m}$ for the modified fibre. A further increase in CB content to $19.8 \mathrm{wt} . \%$ and $23 \mathrm{wt}$ \% increased the conductivity substantially, to $8.8 \times 10^{-6}$ and $0.044 \mathrm{~S} / \mathrm{m}$, respectively. The presence of particulate matter in the fibre structure, however, reduced the tenacity of the fibres to $30-50 \%$ of the value of a standard fibre.

In experiments to measure conductivity of rotor rings and yarns, a remarkable influence of relative humidity present in ambient air was observed. Sorption of water into fibre assemblies with high electrical resistance, e.g., $10^{9}-10^{10} \Omega$, led to a decrease in resistance. In the case of rotor rings manufactured from fibres with $23.1 \mathrm{wt}$ \% CB, however, the initially low volume resistivity of $10 \mathrm{k} \Omega$ increased slightly, most probably due to hygral fibre expansion and adsorption of water onto the fibre surface.

Through a combination of the more rigid CB-containing viscose fibres with elastic polyester fibres, a piezo-sensitive nonwoven fabric was manufactured, which demonstrated pressure sensitivity in the range of very low pressure of 400-1000 Pa. Repetitive load/relaxation cycles demonstrated the repeatability and durability of the sensor mat and the stability of the signal.

The results highlight the potential of CB-incorporated viscose fibres as a cheap functional material for pressure sensor production in smart textile applications. The incorporation of carbon black into the viscose fibres led to a black colour, which limits their application in the visible parts of a garment. However, their use for pressure sensing inside a garment and therapeutic compression textiles, e.g., bandages, in the form of pressure-sensing pads, could be potential applications of the material. The material is of particular interest for sensor design, as the CB-incorporated cellulose fibres are nontoxic, compatible with future recycling, and able to be produced at affordable costs.

The conductive cellulose fibres exhibit high potential for the substitution of nonbiodegradable synthetic material used in other applications and, thus, could become a greener alternative to existing materials used in smart textiles.

Supplementary Materials: The following are available online at http://www.mdpi.com/1996-1944/13/22/5150/s1. Figure S1. Rotor ring and measurement of resistance measurement with multimeter; Figure S2. Experimental set-up for the measurement of volume resistance; Figure S3. Experimental set-up for the measurement of yarn resistance; Figure S4. Experimental set-up for the measurement of resistance as function of pressure; Figure S5. Experimental set-up for the cyclic load/release experiments in a tensile testing unit.

Author Contributions: Conceptualization, Y.Z., D.M., and T.B.; investigation, M.E., Y.Z., D.M., N.K., J.F.T., A.M.-A., and T.B.; methodology, J.U., Y.Z., and T.B.; project administration, D.M.; writing-original draft, J.U., Y.Z., D.M., and T.B.; writing-review and editing, T.B. All authors have read and agreed to the published version of the manuscript.

Funding: This research was funded by Austrian research promotion agency (FFG) K-Project tccv (860474) Textile Competence Centre Vorarlberg and the FFG-talente program.

Acknowledgments: The authors thank Anna-Lena Moosbrugger for technical support in the experimental work.

Data Statement: The datasets generated and/or analysed during the current study are available from the corresponding author on reasonable request.

Conflicts of Interest: The authors declare no conflict of interest.

\section{References}

1. European Commission. Smart Wearables Reflection and Orientation Paper Including Feedback from Stakeholders December 2017; European Commission: Bruxelles, Belgium, 2017.

2. Castano, L.M.; Flatau, A.B. Smart Fabric Sensors and E-Textile Technologies: A Review. Smart Mater. Struct. 2014, 23, 053001. [CrossRef] 
3. Pham, T.; Bechtold, T. Conductive Fibres. In Handbook of Fibres as Advanced Materials; Hu, J.H., Kumar, B., Lu, J., Eds.; Wiley-VCH Verlag: Weinheim, Germany, 2020.

4. Islam, G.M.N.; Ali, A.; Collie, S. Textile Sensors for Wearable Applications: A Comprehensive Review. Cellulose 2020, 27, 6103-6131. [CrossRef]

5. Gonçalves, C.; da Silva, A.F.; Gomes, J.; Simoes, R. Wearable E-Textile Technologies: A Review on Sensors, Actuators and Control Elements. Inventions 2018, 3, 14. [CrossRef]

6. Meyer, J.; Lukowicz, P.; Tröster, G. Textile Pressure Sensor for Muscle Activity and Motion Detection. In Proceedings of the 2006 10th IEEE International Symposium on Wearable Computers, Montreux, Switzerland, 11-14 October 2006; pp. 69-74. [CrossRef]

7. Root, W.; Wright, T.; Caven, B.; Bechtold, T.; Pham, T. Flexible Textile Strain Sensor Based on Copper-Coated Lyocell Type Cellulose Fabric. Polymers 2019, 11, 784. [CrossRef] [PubMed]

8. Pizarro, F.; Villavicencio, P.; Yunge, D.; Rodríguez, M.; Hermosilla, G.; Leiva, A. Easy-to-Build Textile Pressure Sensor. Sensors 2018, 18, 1190. [CrossRef] [PubMed]

9. Rothmaier, M.; Luong, M.P.; Clemens, F. Textile Pressure Sensor Made of Flexible Plastic Optical Fibers. Sensors 2008, 8, 4318-4329. [CrossRef]

10. Nie, B.; Huang, R.; Yao, T.; Zhang, Y.; Miao, Y.; Liu, C.; Liu, J.; Chen, X. Textile-Based Wireless Pressure Sensor Array for Human-Interactive Sensing. Adv. Funct. Mater. 2019, 29, 1-10. [CrossRef]

11. Enokibori, Y.; Suzuki, A.; Mizuno, H.; Shimakami, Y.; Mase, K. E-Textile Pressure Sensor Based on Conductive Fiber and Its Structure. In Proceedings of the 2013 ACM Conference on Pervasive and Ubiquitous Computing Adjunct Publication-UbiComp'13 Adjunct, New York, NY, USA, 8-12 September 2013; pp. 207-210. [CrossRef]

12. Holleczek, T.; Rüegg, A.; Harms, H.; Tröster, G. Textile Pressure Sensors for Sports Applications. In Proceedings of the 2010 IEEE Sensors, Kona, HI, USA, 1-4 November 2010; pp. 732-737. [CrossRef]

13. Tessarolo, M.; Possanzini, L.; Campari, E.G.; Bonfiglioli, R.; Violante, F.S.; Bonfiglio, A.; Fraboni, B. Adaptable Pressure Textile Sensors Based on a Conductive Polymer. Flex. Print. Electron. 2018, 3, 034001. [CrossRef]

14. Kim, M.; Kim, H.; Park, J.; Jee, K.K.; Lim, J.A.; Park, M.C. Real-Time Sitting Posture Correction System Based on Highly Durable and Washable Electronic Textile Pressure Sensors. Sens. Actuators A Phys. 2018, 269, 394-400. [CrossRef]

15. Lee, J.; Kwon, H.; Seo, J.; Shin, S.; Koo, J.H.; Pang, C.; Son, S.; Kim, J.H.; Jang, Y.H.; Kim, D.E.; et al. Conductive Fiber-Based Ultrasensitive Textile Pressure Sensor for Wearable Electronics. Adv. Mater. 2015, 27, 2433-2439. [CrossRef]

16. Qi, K.; Wang, H.; You, X.; Tao, X.; Li, M.; Zhou, Y.; Zhang, Y.; He, J.; Shao, W.; Cui, S. Core-Sheath Nanofiber Yarn for Textile Pressure Sensor with High Pressure Sensitivity and Spatial Tactile Acuity. J. Colloid Interface Sci. 2020, 561, 93-103. [CrossRef]

17. Carvalho, H.; Tama, D.; Gomes, P.; Abreu, M.J.; Yao, Y.; Souto, A.P. Flexible Piezoresistive Pressure Sensors for Smart Textiles. IOP Conf. Ser. Mater. Sci. Eng. 2018, 459, 012035. [CrossRef]

18. Li, T.; Chen, L.; Yang, X.; Chen, X.; Zhang, Z.; Zhao, T.; Li, X.; Zhang, J. A Flexible Pressure Sensor Based on an MXene-Textile Network Structure. J. Mater. Chem. C 2019, 7, 1022-1027. [CrossRef]

19. Herbaut, A.; Simoneau-Buessinger, E.; Barbier, F.; Cannard, F.; Guéguen, N. A Reliable Measure of Footwear Upper Comfort Enabled by an Innovative Sock Equipped with Textile Pressure Sensors. Ergonomics 2016, 59, 1327-1334. [CrossRef] [PubMed]

20. Lim, S.J.; Bae, J.H.; Han, J.H.; Jang, S.J.; Oh, H.J.; Lee, W.; Kim, S.H.; Ko, J.H. Foldable and Washable Fully Textile-Based Pressure Sensor. Smart Mater. Struct. 2020, 29, 055010. [CrossRef]

21. Zhou, B.; Koerger, H.; Wirth, M.; Zwick, C.; Martindale, C.; Cruz, H.; Eskofier, B.; Lukowicz, P. Smart Soccer Shoe. In Proceedings of the 2016 ACM International Symposium on Wearable Computers-VISWC'16, New York, NY, USA, 12-16 September 2016; pp. 64-71. [CrossRef]

22. Meyer, J.; Arnrich, B.; Schumm, J.; Troster, G. Design and Modeling of a Textile Pressure Sensor for Sitting Posture Classification. IEEE Sens. J. 2010, 10, 1391-1398. [CrossRef]

23. Xu, W.; Huang, M.C.; Amini, N.; He, L.; Sarrafzadeh, M. ECushion: A Textile Pressure Sensor Array Design and Calibration for Sitting Posture Analysis. IEEE Sens. J. 2013, 13, 3926-3934. [CrossRef] 
24. Zhou, B.; Cheng, J.; Sundholm, M.; Lukowicz, P. From Smart Clothing to Smart Table Cloth: Design and Implementation of a Large Scale, Textile Pressure Matrix Sensor. In Lecture Notes in Computer Science (Including Subseries Lecture Notes in Artificial Intelligence and Lecture Notes in Bioinformatics); Springer Nature Switzerland: Cham, Switzerland, 2014; Volume 8350 LNCS, pp. 159-170. [CrossRef]

25. Cheng, J.; Sundholm, M.; Hirsch, M.; Zhou, B.; Palacio, S.; Lukowicz, P. Application Exploring of Ubiquitous Pressure Sensitive Matrix as Input Resource for Home-Service Robots. Adv. Intell. Syst. Comput. 2015, 345, 359-371. [CrossRef]

26. Cheng, J.; Sundholm, M.; Zhou, B.; Hirsch, M.; Lukowicz, P. Smart-Surface: Large Scale Textile Pressure Sensors Arrays for Activity Recognition. Pervasive Mob. Comput. 2016, 30, 97-112. [CrossRef]

27. Liu, M.; Pu, X.; Jiang, C.; Liu, T.; Huang, X.; Chen, L.; Du, C.; Sun, J.; Hu, W.; Wang, Z.L. Large-Area All-Textile Pressure Sensors for Monitoring Human Motion and Physiological Signals. Adv. Mater. 2017, 29, 1-9. [CrossRef]

28. Fraboni, B. Sensors Performance. Sensors 2019, 19, 4686. [CrossRef]

29. Kim, G.; Vu, C.C.; Kim, J. Single-Layer Pressure Textile Sensors Withwoven Conductive Yarn Circuit. Appl. Sci. 2020, 10, 2877. [CrossRef]

30. Kim, K.; Jung, M.; Jeon, S.; Bae, J. Robust and Scalable Three-Dimensional Spacer Textile Pressure Sensor for Human Motion Detection. Smart Mater. Struct. 2019, 28, 065019. [CrossRef]

31. Wang, Y.; Hua, T.; Zhu, B.; Li, Q.; Yi, W.; Tao, X. Novel Fabric Pressure Sensors: Design, Fabrication, and Characterization. Smart Mater. Struct. 2011, 20, 065015. [CrossRef]

32. Zhou, Z.; Li, Y.; Cheng, J.; Chen, S.; Hu, R.; Yan, X.; Liao, X.; Xu, C.; Yu, J.; Li, L. Supersensitive All-Fabric Pressure Sensors Using Printed Textile Electrode Arrays for Human Motion Monitoring and Human-Machine Interaction. J. Mater. Chem. C 2018, 6, 13120-13127. [CrossRef]

33. Luo, N.; Zhang, J.; Ding, X.; Zhou, Z.; Zhang, Q.; Zhang, Y.T.; Chen, S.C.; Hu, J.L.; Zhao, N. Textile-Enabled Highly Reproducible Flexible Pressure Sensors for Cardiovascular Monitoring. Adv. Mater. Technol. 2018, 3, 1-8. [CrossRef]

34. Lou, C.; Wang, S.; Liang, T.; Pang, C.; Huang, L.; Run, M.; Liu, X. A Graphene-Based Flexible Pressure Sensor with Applications to Plantar Pressure Measurement and Gait Analysis. Materials 2017, 10, 1068. [CrossRef]

35. Liu, W.; Liu, N.; Yue, Y.; Rao, J.; Luo, C.; Zhang, H.; Yang, C.; Su, J.; Liu, Z.; Gao, Y. A Flexible and Highly Sensitive Pressure Sensor Based on Elastic Carbon Foam. J. Mater. Chem. C 2018, 6, 1451-1458. [CrossRef]

36. Root, W.; Aguiló-Aguayo, N.; Pham, T.; Bechtold, T. Conductive Layers through Electroless Deposition of Copper on Woven Cellulose Lyocell Fabrics. Surf. Coat. Technol. 2018, 348, 13-21. [CrossRef]

37. Mayer, D. Optimierung Der Herstellung Funktionalisierter Viskosefasern Anhand Eines Verfahrenstechnischen Ansatzes. Master's Thesis, Technical University Munich, Chair of Biogene Polymers, Munich, Germany, 2017.

Publisher's Note: MDPI stays neutral with regard to jurisdictional claims in published maps and institutional affiliations.

(C) 2020 by the authors. Licensee MDPI, Basel, Switzerland. This article is an open access article distributed under the terms and conditions of the Creative Commons Attribution (CC BY) license (http://creativecommons.org/licenses/by/4.0/). 